\title{
Child consent in South African law: Implications for researchers, service providers and policy-makers
}

\author{
Ann Strode, Catherine Slack, Zaynab Essack
}

Children under 18 are legal minors who, in South African law, are not fully capable of acting independently without assistance from parents/legal guardians. However, in recognition of the evolving capacity of children, there are exceptional circumstances where the law has granted minors the capacity to act independently. We describe legal norms for child consent to health-related interventions in South Africa, and argue that the South African Parliament has taken an inconsistent approach to: the capacity of children to consent; the persons able to consent when children do not have capacity; and restrictions on the autonomy of children or their proxies to consent. In addition, the rationale for the differing age limitations, capacity requirements and public policy restrictions has not been specified. These inconsistencies make it difficult for stakeholders interacting with children to ensure that they act lawfully.

S Afr Med J 2010; 100: 247-249.
Children under the age of 18 are legal minors and, accordingly, have limited legal capacity to act independently without the assistance of an adult. ${ }^{1}$ However, South African legislators recognised that children have evolving capacity, and consequently passed laws that permit children to make certain decisions independently. Some of these laws are in operation, while other provisions will be implemented in the future.

\section{Medical treatment}

Currently, children can consent independently to medical treatment from the age of 14; those below 14 require consent from a parent, legal guardian or other designated person. ${ }^{2}$ In the future, children will be able to consent to medical treatment from the age of 12 , if they have 'sufficient maturity'. ${ }^{3}$

\section{HIV testing}

Currently, children can consent independently to an HIV test from the age of 12 , when it is in their best interests, and below the age of 12 if they demonstrate 'sufficient maturity'; i.e. they must be able to understand the benefits, risks and social implications of an HIV test. ${ }^{4,5}$ This norm is not likely to change in the immediate future.

\section{Access to contraceptives}

Currently, children can consent to contraceptives and contraceptive advice from the age of $12 .^{6}$ This norm is not likely to change in the immediate future.

\section{Termination of pregnancy}

Currently, girls can consent to a termination of pregnancy at any age. ${ }^{7}$ This norm is not likely to change in the immediate future.

\section{Operations}

Currently, children cannot consent independently to a medical operation until they are $18 .{ }^{2}$ When s129(3) of the Children's Act

\author{
Faculty of Law and HIV/AIDS Vaccines Ethics Group, University of KwaZulu- \\ Natal, Pietermaritzburg \\ Ann Strode, LLM \\ HIV/AIDS Vaccines Ethics Group, University of KwaZulu-Natal \\ Catherine Slack, MA Clin Psych \\ Zaynab Essack, MSocSci Res Psych
}

comes into operation, a child over the age of 12 may consent to surgical operations if he/she (i) has 'sufficient maturity and has the mental capacity to understand the benefits, risks, social and other implications of the surgical operation'; and (ii) is assisted by a parent or guardian. ${ }^{8}$

\section{Male circumcision}

Currently, boys are able to consent independently to circumcision only when they are 18 as the procedure is classified as an operation. In the future, when s12(8) of the Children's Act comes into operation, boys below age 16 can only be circumcised for 'religious' or 'medical reasons on the recommendation of a medical practitioner' whereas those above 16 may undergo circumcision for any reason. ${ }^{10}$ Boys over 16 must receive counselling prior to the circumcision, and they have the right to refuse circumcision. ${ }^{11}$

\section{Health research}

Currently, there is no clear legal statute specifying when children can independently consent to research; however, there are ethical norms. For clinical trials, these norms require parental consent and child assent. ${ }^{12}$ For other forms of health research, these norms generally require consent from a parent; however, they do allow independent consent from older adolescents for low-risk research..$^{13}$ In the future, when s71 of the National Health Act is implemented, parental/legal guardian consent will be mandatory for all health research; in addition, children will be required to 'consent' alongside their parent if they have 'sufficient understanding'. ${ }^{5}$ There is no mention in this Act of the need to obtain assent from a child who does not have the required understanding to consent to the research. However, this would be considered good practice, considering that the Children's Act specifies that children have a right to participate in an appropriate way in matters that affect them. ${ }^{14}$

\section{Sex}

Currently, it is an offence to have sex below the age of 16 , even when sex is consensual..$^{15}$ This means that if one or both of the persons engaged in consensual sex are below the age of 16 , they are committing a criminal offence. This norm is not likely to change in the immediate future. 


\section{Discussion}

The range of consent norms that have been applied across a spectrum of health-related interventions indicate an inconsistent approach to children's emerging autonomy:

1. For some procedures, children are given the capacity to consent on reaching a specified age; for other procedures, they must reach the specified age and demonstrate capacity requirements; and yet for other related procedures, there are neither age nor capacity requirements (Table I). For example, according to the future framework, a child can consent to an HIV test and access to contraceptives on reaching age 12 alone; however, for medical treatment, they must be 12 and demonstrate that they have 'sufficient maturity'. Since all these interventions are health-related, it seems inconsistent not to treat them alike and not have, for example, a maturity criterion for all.

A further problem with the inconsistent approach to capacity is that, concerning research (where in the future children will not be able to consent without assistance), a child's emerging autonomy is not sufficiently recognised. In the future framework, the capacity requirements for research will be extremely stringent, and children under the age of 18 will never be able to consent independently to any form of health research regardless of the risk level. Thus, consent norms for research participation will not appropriately reflect the reality that research is of varying complexity and risk. For simple and low-risk research (such as asking older adolescents for their views on violence on TV), exceptions to the norm of parental consent may be appropriate, provided that other protections are in place, such as ethical review. This strict requirement is out of keeping with socio-behavioural data indicating that older children can understand many components of research. ${ }^{16}$ This observation suggests that their enrolment in low-risk studies without parental consent may be approvable in some instances.
2. There are different approaches to the adult who is considered competent to provide proxy consent when the child does not have capacity (Table II). For operations, the Children's Act refers to the need for the 'assistance' of a parent or guardian; $;$ and for research, proxy consent is limited to a parent or legal guardian, effectively undermining research for and with orphans. For other health interventions, e.g. male circumcision and HIV testing, the consent of a range of additional persons including caregivers is permitted.

3. Different norms apply as to when the activity may be consented to either by children themselves or a proxy consenter (Table III). In the future, 3 health-related interventions may only be undertaken if public policy criteria are met (i.e. special protections exist). These are HIV testing, male circumcision and research which may only be undertaken if they serve the legitimate purpose described in legislation (Table III).

The rationale for limiting HIV testing appears to be a desire to end testing that is used to discriminate against children. ${ }^{17}$ However, the justification for limiting male circumcision is less clear, given the health benefits, including evidence that medically circumcised men are at substantially reduced risk of contracting HIV from an infected female ${ }^{18}$ and the additional protections in the Act regarding consent, child participation, best interests and confidentiality. These limitations may serve as a barrier to children accessing such services. The rationale for limiting non-therapeutic research with children to research that has been approved by the Minister of Health is unclear, and results in an overly restrictive framework for nontherapeutic research involving minors. ${ }^{19}$

4. Different procedural obligations are placed on persons obtaining consent during some, but not other, health interventions. For example, for pregnancy terminations, HIV testing and male circumcision, counselling must be part of the consent process - yet this is not required for other healthrelated interventions such as access to contraceptives (where

Table I. Health procedures/interventions for which children can consent independently: current and future

\begin{tabular}{lcc}
\hline $\begin{array}{l}\text { Procedure/ } \\
\text { intervention }\end{array}$ & $\begin{array}{l}\text { Age at which child can consent } \\
\text { independently now }\end{array}$ & $\begin{array}{l}\text { Age at which child can consent } \\
\text { independently in the future }\end{array}$ \\
\hline $\begin{array}{l}\text { Medical treatment } \\
\text { Operations }\end{array}$ & 14 & $\begin{array}{c}12+\text { 'sufficient maturity' } \\
12+\text { 'sufficient maturity' }+ \\
\text { parental/guardian assistance } \\
\end{array}$ \\
HIV testing & 18 & 12 \\
Access to contraceptives & 12 & 12 \\
Terminations of pregnancy & 12 & Any age \\
Male circumcision & Any age & 16 \\
Research & 18 & 18 \\
\hline
\end{tabular}

Table II. Persons who can consent when children do not have capacity: current and future

\begin{tabular}{|c|c|c|}
\hline Activity/intervention & Currently & In the future \\
\hline Research & No legal guidelines & Parent/legal guardian must consent \\
\hline Medical treatment & $\begin{array}{l}\text { Parent/legal guardian and a range } \\
\text { of other persons can consent }\end{array}$ & $\begin{array}{l}\text { Parent/legal guardian, caregiver and a } \\
\text { range of other persons can consent }\end{array}$ \\
\hline Operations & Parent/legal guardian must consent & Parent/legal guardian must assist \\
\hline HIV testing & $\begin{array}{l}\text { Parent/legal guardian and a range } \\
\text { of other persons can consent }\end{array}$ & $\begin{array}{l}\text { Parent/legal guardian and a range of } \\
\text { other persons can consent }\end{array}$ \\
\hline Male circumcision & $\begin{array}{l}\text { Parent/legal guardian must } \\
\text { consent to operation }\end{array}$ & $\begin{array}{l}\text { Parent/legal guardian and a range of } \\
\text { other persons can consent }\end{array}$ \\
\hline
\end{tabular}


Table III. Public policy restraints on health-related interventions

\begin{tabular}{ll}
\hline Activity/intervention & Public policy criterion \\
\hline HIV testing (current) & Must be in the best interests of the child \\
Male circumcision (future) & $\begin{array}{l}\text { For boys under 16, must be undertaken for religious or medical reasons on the } \\
\text { recommendation of a medical practitioner }\end{array}$ \\
Research (future) & $\begin{array}{l}\text { Therapeutic research must be in the best interests of the child. Non-therapeutic research } \\
\text { must be approved by the Minister of Health }\end{array}$ \\
\hline
\end{tabular}

Table IV. Procedural obligations during the consent process

\begin{tabular}{ll}
\hline Activity/intervention & Procedural obligations during the consent process \\
\hline Termination of pregnancy & Counselling must be offered before the termination of pregnancy \\
HIV testing & Pre- and post-test counselling must be provided \\
Male circumcision & Counselling must be provided to boys of 16 and older before the decision to undergo \\
& circumcision. \\
\hline
\end{tabular}

counselling may go some way to reduce high-risk sexual behaviours) (Table IV).

\section{Conclusions}

Parliament has clearly adopted an inconsistent approach in setting consent norms for children. It is difficult to establish any pattern between a child's emerging capacity and the norms for various health interventions. There are several conceptual and practical difficulties for stakeholders trying to meet their legal obligations.

Researchers: Obtaining consent for the participation of children in HIV prevention trials is extremely complex; children under 18 will require consent from a parent or legal guardian, but will have the capacity to consent independently to some procedures and interventions within these trials. For example, children aged 12 and older who are enrolled in prevention trials should consent independently to HIV tests in such trials, and child research participants who are 14 and older should consent independently to procedures that amount to a diagnosis and treatment (e.g. STI treatment) within such trials. Obtaining consent will require a sound understanding of what information parents will and will not have access to, and may result in complicated consent processes. Researchers must also keep abreast of the law to establish when the age cut-offs for consent may change.

Service-providers and researchers: It is not clear what the additional capacity requirements outlined in the law actually entail. How should a service provider establish 'sufficient maturity'? It could merely entail cognitive understanding, as outlined in the law on HIV testing, where sufficient maturity is described as understanding the benefits, risks and social implications of the intervention. ${ }^{4}$ However, maturity could also entail stable values, longer-term perspectives or impulse control..$^{20}$ Furthermore, it appears that norms that allow children to consent independently to services in some instances may jar with other legal requirements. For example, children can access sexual health services from age 12, whereas sex under age 16 is illegal. Medical practitioners (and others) are under a statutory duty to report under-age sex..$^{21}$ Therefore, service providers and researchers acting lawfully in terms of the Children's Act by providing contraceptives to a sexually active 13-year-old will be acting unlawfully in terms of the

Sexual Offences Act if they fail to report the child's engaging in a sexual offence to the police. ${ }^{22}$

Policy-makers: Parliament should justify its inconsistent approach in the setting of consent norms for children. In the future, there will generally be greater consistency, as Parliament is lowering the age to 12 for consent to a range of medically related interventions. However, Parliament has introduced a range of different obligations in many of these interventions that should be reconsidered and/or carefully defended. For example, the restrictions on male circumcision need further thought, given the rampant HIV epidemic. ${ }^{18}$ Also, lowering the age at which children may utilise services independently may increase their access to services; however, it is not clear whether the protections put in place will ensure that children are able to manage the implications of such services.

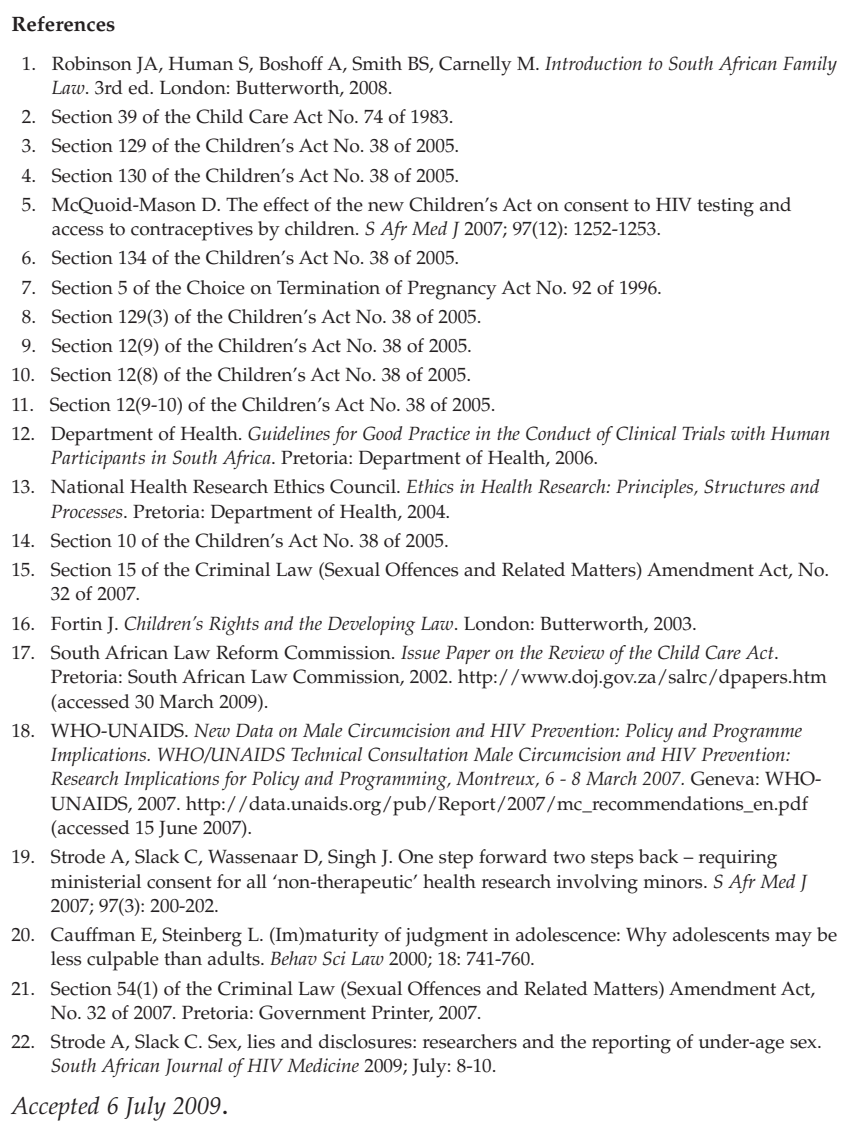

